\title{
Panorama de recursos en internet para investigar en cine primitivo
}

\author{
Mónica BARRIEntos-Bueno \\ Universidad de Sevilla \\ mbarrientos@us.es
}

Resumen:

Se presentan y analizan varios de los recursos en línea disponibles para complementar la investigación básica de campo realizada en archivos, hemerotecas y filmotecas en el proceso de historiar cine hasta 1915 aproximadamente, destacándose así sus aspectos más relevantes y en qué medida pueden contribuir. Para clarificar el acercamiento, los citados recursos se presentan clasificados en función de la naturaleza de sus contenidos e información que ofrecen al investigador a raíz de la propia experiencia de la autora, investigadora de los inicios del cine en Sevilla.

Palabras clave: Historia del Cine; Orígenes del Cine; Cine Primitivo; Investigación; Internet; Bases de datos

\section{Panoramic View over Internet Sources for Researching in Primitive Cinema}

\begin{abstract}
:
Some online resources are presented and analysed for supplementing the basic field research made in archives, newspapers libraries and film archives for pre-1915 cinema History studies. This paper is focused on their most relevant aspects and how they can contribute. For clearing this approach, the resources are introduced classified by their nature and it is commented the information offered to the researcher from the author own experience, historian in the beginnings of cinema in Seville.
\end{abstract}

Keywords: History of Cinema; Origins of Cinema; Primitive Cinema; Researching; Internet; Databases

\section{Referencia normalizada:}

Barrientos Bueno, M. (2013) Panorama de recursos en Internet para investigar en cine primitivo. Historia y Comunicación Social. Vol. 18 No Especial Noviembre. Págs. 481-497.

Sumario: 1. Introducción. 2. Metodología. 3. Catálogos filmográficos de grandes productoras. 3.1. Pathé Frères. 3.2. Gaumont Pathé Archives. 3.3. Edison. 4. Bases de datos de filmotecas: el ámbito nacional. 5. Otras bases de datos de interés. 6. Webs especializadas en el cine de los primeros tiempos. 7. Acceso a copias bibliográficas digitales. 8. Conclusiones. 9. Bibliografía.

\section{Introducción}

Investigar sobre los inicios del cine y su discurrir durante los primeros años, especialmente en lo que respecta a su implantación en una localidad o región concretas, se ha fundamentado tradicionalmente en un minucioso trabajo de campo en archivos, hemerotecas y filmotecas para rastrear entre expedientes administrativos, páginas 
de periódicos y publicaciones de la época, además de diverso material publicitario impreso conservado.

Las labores habituales en este ámbito suponen inventariar aparatos de proyección y tomavistas empleados, localizar espacios de diversa naturaleza e índole donde se han realizado exhibiciones, identificar y hacer relación de títulos de filmes de los cuales hay constancia de su proyección, conocer el nivel de difusión del espectáculo, además de cuestiones relacionadas con la recepción entre otros aspectos de interés. Sumergirse en la investigación de cualquiera de estos aspectos, u otros relacionados con los orígenes del cine y sus primeros momentos, puede conllevar el verse inmerso en un océano de necesidades tras la tarea llevada a cabo en un archivo o hemeroteca, las cuales no siempre se sabe cómo satisfacer. Así sucede, por ejemplo, al intentar vincular o identificar los títulos de las vistas de las que hay constancia de su exhibición en una ciudad con cintas producidas en ese marco temporal.

Desde este punto de partida se presenta un análisis de varios de los recursos en línea disponibles para completar la investigación básica de campo realizada en archivos, hemerotecas y filmotecas en el proceso de profundizar en los primeros años del cine, muchos de ellos creemos poco conocidos para algunos historiadores. Se destacan sus aspectos más relevantes y en qué medida pueden contribuir a la investigación. En definitiva, el propósito es trazar un mapa de fuentes útiles para los investigadores tanto especializados como noveles en el periodo de "cine de atracciones", siguiendo la terminología de André Gaudreault (2011), con el fin de conocer el amplio abanico de posibilidades a su alcance en un simple golpe de ratón.

En lo que respecta al estado de la cuestión, no abundan los estudios metodológicos al respecto que arrojen luz sobre las fuentes en línea disponibles para este campo tan específico y delimitado de la Historia. La mayor parte de los catálogos difundidos y conocidos por los investigadores son en formato papel lo cual, precisamente por su propia naturaleza, puede suponer un obstáculo para su fácil acceso. Entre los catálogos y fuentes habituales de referencia se encuentran los de la producción Lumière (Aubert y Seguin, 1995), Pathé (Bousquet, 1994-2004), Star-Film (Malthête, Malthête-Méliès y Quévrain, 1981), Edison (Musser, 1997) y Biograph (Browser, 1973 y Niver, 1973), pasando por otros que tienen un carácter más global, ya sea para la producción estadounidense (American Film Institute, 1988, Musser, 1984 y Savada, 1995), la británica (British Film Institute, 1966 y Gifford, 2001), todos los depósitos de derechos de autor (Niver, 1967 y Library of Congress, 1953 y 1955).

\section{Metodología}

Los recursos presentados han sido recopilados, a lo largo de los últimos años, por la autora a raíz de las necesidades surgidas a partir de sus propias investigaciones sobre el desarrollo y funcionamiento de los primeros años del cine en Sevilla desde el punto de vista de la exhibición, dando especial énfasis a la identificación filmográfica 
de las cintas proyectadas, así como los aparatos empleados y algunos aspectos relacionados con la recepción.

Para presentar de la manera más clara posible la variedad de fuentes disponibles, se ha realizado una clasificación basada en la propia naturaleza de la mismas que coincide con los epígrafes del texto que sigue. Pero no se trata tan sólo de exponer una tras otra una serie de enlaces web, también se han sometido a un análisis del que se han extraído los contenidos e informaciones que aportan, valorados desde su relevancia para el investigador.

\section{Catálogos filmográficos de grandes productoras}

\subsection{Pathé Frères}

Las ventajas del mundo digital son muchas, como todos sabemos; en nuestro caso se traduce en la posibilidad de acceder fácilmente a un amplio abanico de catálogos filmográficos de las principales productoras de la época, hasta hace no mucho disponibles únicamente en formato libro impreso como el de Pathé Frères (Bousquet, 1994-2004) o Gaumont (d'Hugues y Muller, 1986). De esta manera, la identificación certera de títulos exhibidos en cualquier localidad se facilita y agiliza en gran medida.

\section{Figura 1}
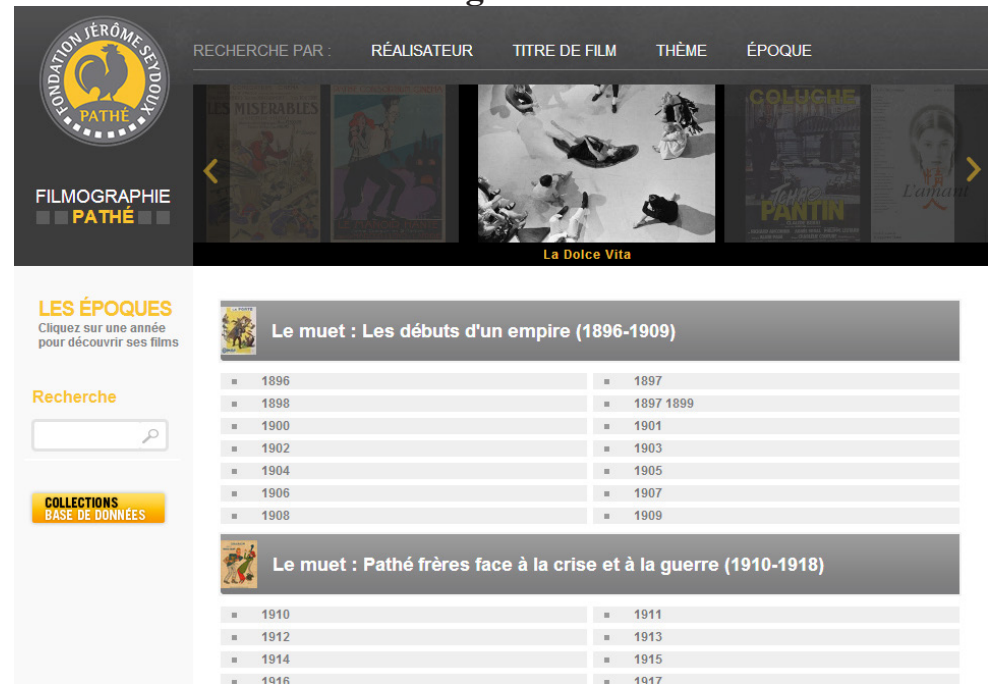

La producción francesa es la que monopoliza mayoritariamente el mercado internacional hasta el inicio de la I Guerra Mundial: entre 1899 y 1913 la firma gala Pathé Frères, afincada originalmente en Vicennes, ostenta el control mundial de la boyante industria cinematográfica (Bousquet, 1994: 48). Ello tiene reflejo en el número de 
catálogos de productoras existentes en línea; entre los más relevantes se encuentra precisamente el de Pathé Frères, cuyo acceso es posible gracias a la labor emprendida por la Fondation Jérôme Seydoux Pathé (http://filmographie.fondation-jeromeseydoux-pathe.com/) (la figura 1 muestra una imagen de la interfaz). Abarca un amplio marco temporal que excede los márgenes de los comienzos del cine y llega a la actualidad. La búsqueda puede realizarse por diferentes criterios: director, título, época y temática/género, o directamente introduciendo el término de interés.

Los resultados de la búsqueda arrojan interesantes datos relativos a las cintas, los cuales ayudan a sustentar atribuciones con títulos exhibidos de los que habitualmente se conocen pocos detalles e, incluso también, en ocasiones se incluyen elementos gráficos originales como afiches con los que se publicitaba el filme objeto de la indagación en el catálogo. Entre las informaciones que se aportan se encuentra el número de catálogo de la cinta (indispensable para su inequívoca identificación internacional), género, producción y edición, realizador, intérpretes, escenario o fuente argumental, director de fotografía y responsable de trucajes, metraje, número de cuadros que la componen, código telegráfico para pedidos, una sinopsis argumental (más o menos pródiga en detalles según el título) y una relación de fuentes hemerográficas y bibliográficas (esencialmente en francés y español), con las que ampliar datos sobre la vista animada consultada (como muestra, la figura 2 presenta la pestaña de datos generales de la Vie et Passion de N. S. Jésus Christ: Passion y Mort (Zecca, 1907).

\section{Figura 2}

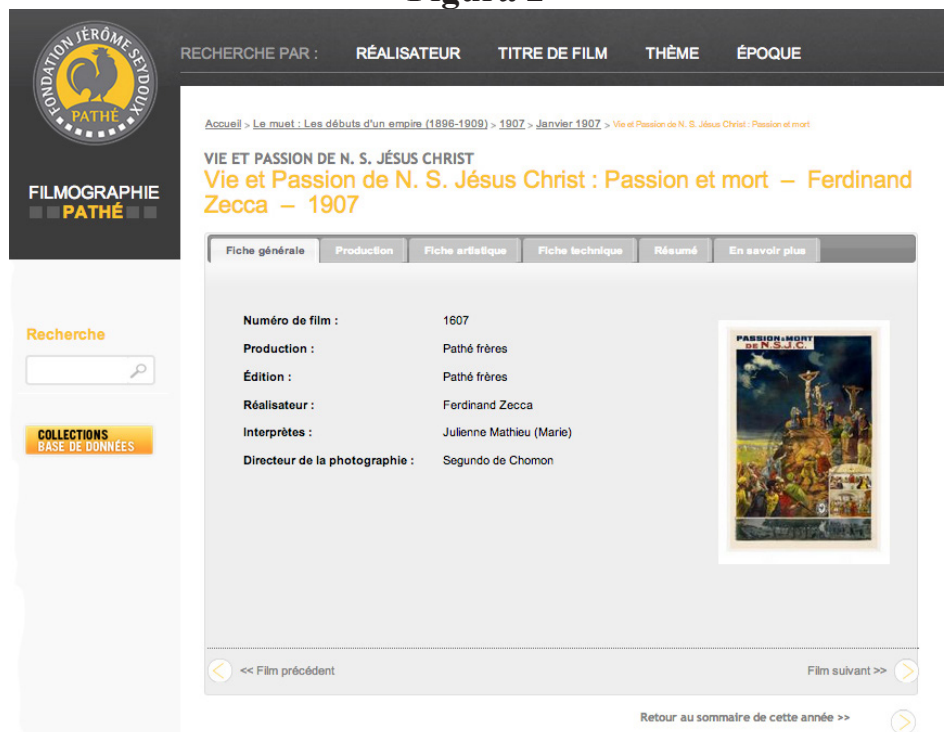

La base de datos de la Fondation Jérôme Seydoux Pathé también permite abrir la búsqueda a otros materiales de un grupo que asciende a varios miles de ejemplares: afiches y materiales publicitarios, dosieres administrativos, fotografías y publicacio- 
nes periódicas, entre otros recursos de interés que tienen a disposición de los investigadores en acceso libre, sin registro previo.

\subsection{Gaumont Pathé Archives}

El catálogo filmográfico en línea Gaumont Pathé Archives (http://www.gaumontpathearchives.com/) está esencialmente dedicado a producción documental e imágenes de actualidad, aunque al margen de su especialización la navegación por el mismo hace posible hallar vistas de ficción de los primeros tiempos de Gaumont y Pathé Fréres. Permite la búsqueda en inglés y francés dentro de un amplio fondo archivístico integrado por 14.000 horas de vídeo, 250.000 documentos y 17.000 cintas de imágenes documentales de diferentes temáticas que van desde la historia y la sociedad, pasando por la política y la cultura, entre otras (véase en la figura 3 una imagen de la portada).

\section{Figura 3}

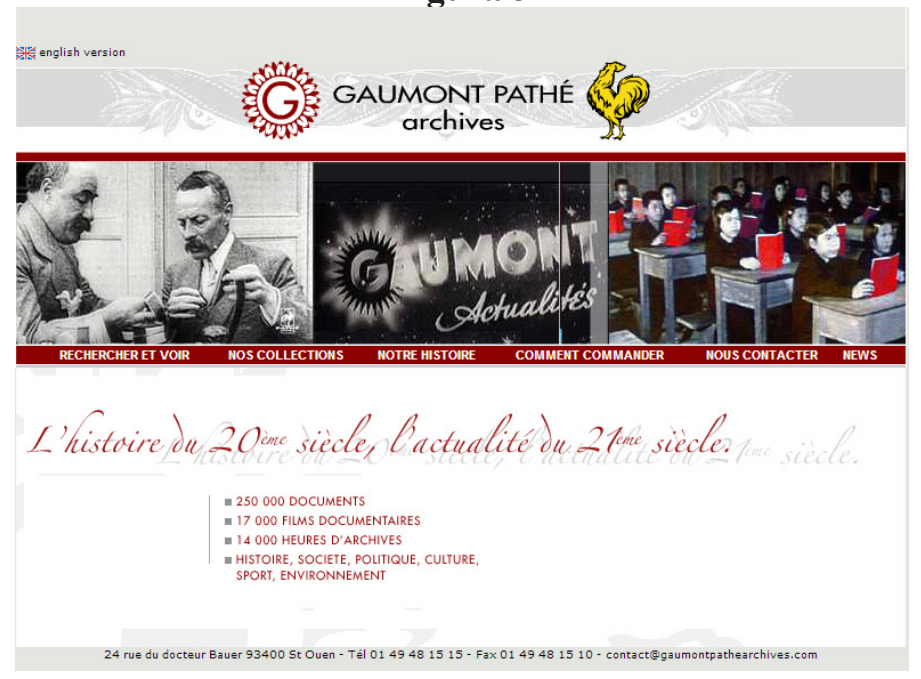

Es posible restringir la búsqueda en gran medida ya sea por fecha, palabra clave o elemento del título sobre el que se indaga. La ficha de cualquiera de las vistas recuperadas proporciona, en el apartado de descripción, varios datos de interés para el investigador: número de referencia, colección a la que pertenece, duración, si es en color o blanco y negro, título original, fecha de toma y/o estreno, género, sinopsis contenida en el catálogo original de la época, palabras clave y observaciones (véase una muestra de ello con la figura 4, donde se presenta la ficha de Le tour du monde d'un policier (Lepine, 1906). 


\section{Figura 4}

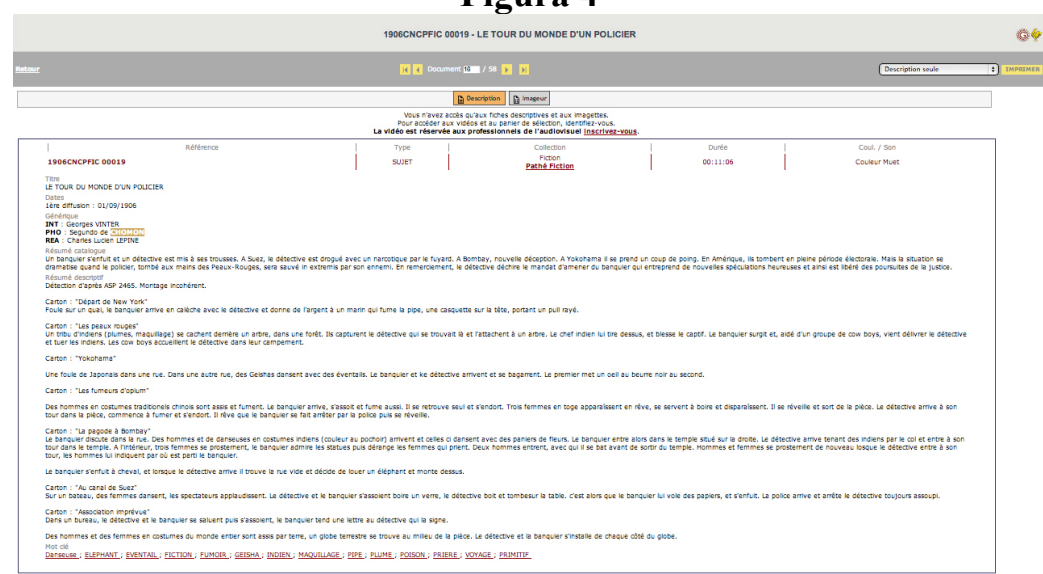

El acceso libre a la base de datos, sin registro como en el caso anterior, permite recuperar un número variable de capturas con marca de agua y código de tiempo del filme buscado (tal como se observa en la figura 5 con las correspondientes a Christophe Colomb (Heilbronn, 1904). Si el usuario se registra accede, además, a un completo storyboard de capturas del film de su interés (no a la selección ofrecida al consultor anónimo) y al visionado de varios minutos, a modo de previo (si fuera de su interés se puede solicitar, previo pago, una copia).

\section{Figura 5}

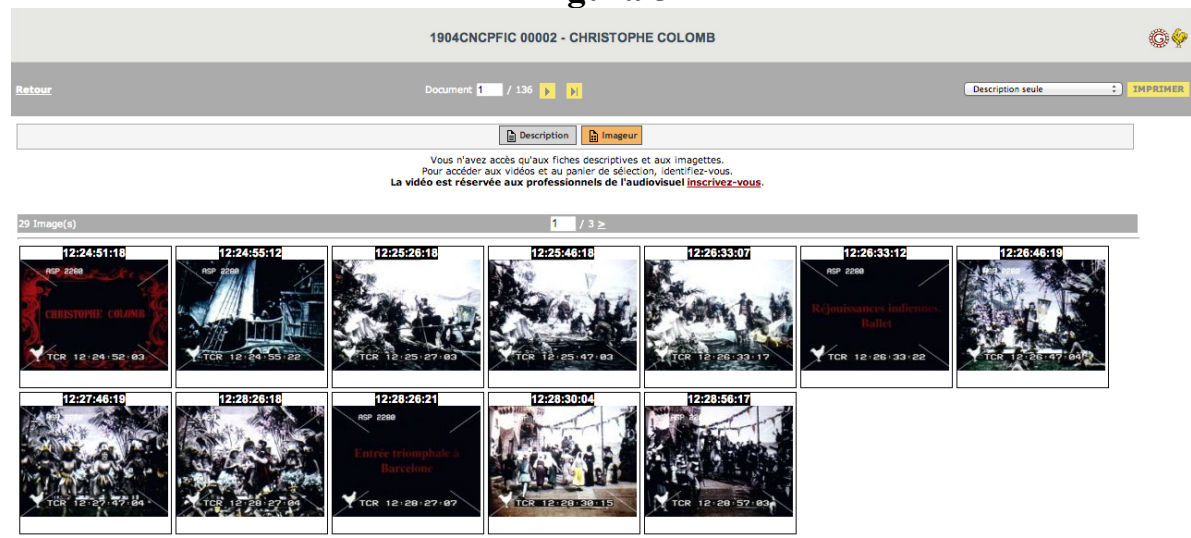

\subsection{Edison}

La firma norteamericana Edison Manufacturing Company tiene, además de parte de su producción accesible en formato impreso (Musser, 1997), su catálogo completo también en línea y con libre acceso a la integridad de su contenido, incluidos el visio- 
nado y descarga (en varios formatos aunque en baja calidad) de sus vistas animadas. La página alojada en el Library of Congress de Estados Unidos dedicada a Edison en el American Memory Collections (http://memory.loc.gov/ammem/edhtml/edhome. $\mathrm{html}$ ) hace posible buscar entre imágenes en movimiento y grabaciones sonoras realizadas por su compañía (tal como se puede observar con la figura 6 , portada de la página).

\section{Figura 6}

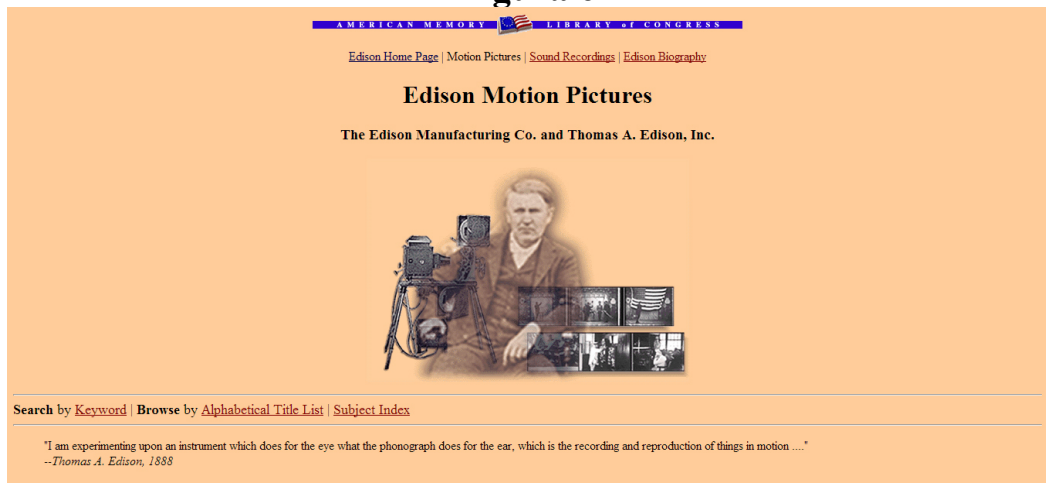

Los datos que se recuperan de cada registro van encabezados por tres fotogramas, enlaces para su descarga en tres formatos de vídeo a baja resolución todos ellos, títulos alternativos por los que también es conocida, información de copyright, sinopsis argumental, intérpretes, operador de cámara, datos de filmación, fuentes de catalogación y varias palabras clave (véase como ejemplo la figura 7 con la ficha de Mary Irwin Kiss (1896).

Figura 7

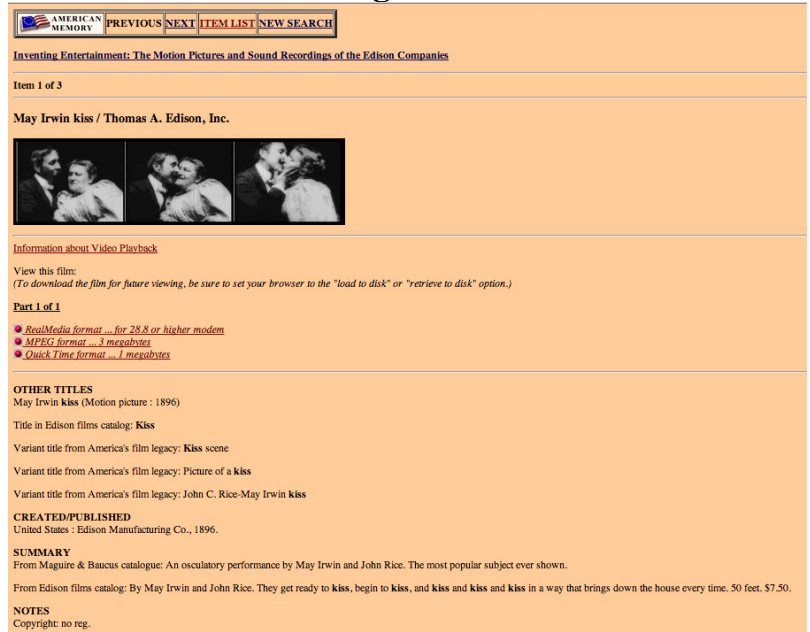




\section{Bases de datos de filmotecas: ámbito nacional}

Las bases de datos filmográficas nacionales resultan también fuentes de gran interés al abrir un amplio abanico de posibilidades por reunir las producciones de un país de manera organizada. La Silent Movie del American Film Institute (http://www.afi. $\mathrm{com} / \mathrm{members} / \mathrm{catalog} / \mathrm{silentHome}$.aspx? $\mathrm{s}=1$ ) abarca todo el periodo mudo norteamericano, entre 1893 y 1930, con lo que reúne unas 25.000 entradas. El elemento añadido a los datos comunes en otros catálogos es que, en muchos casos, las fichas de la base de datos se han enriquecido con informaciones contrastadas adicionales que aumentan el valor del material recuperado (la figura 8 permite conocer la interfaz de una ficha recuperada, en este caso de $A$ Trip to the Moon (Méliès, 1902).

\section{Figura 8}

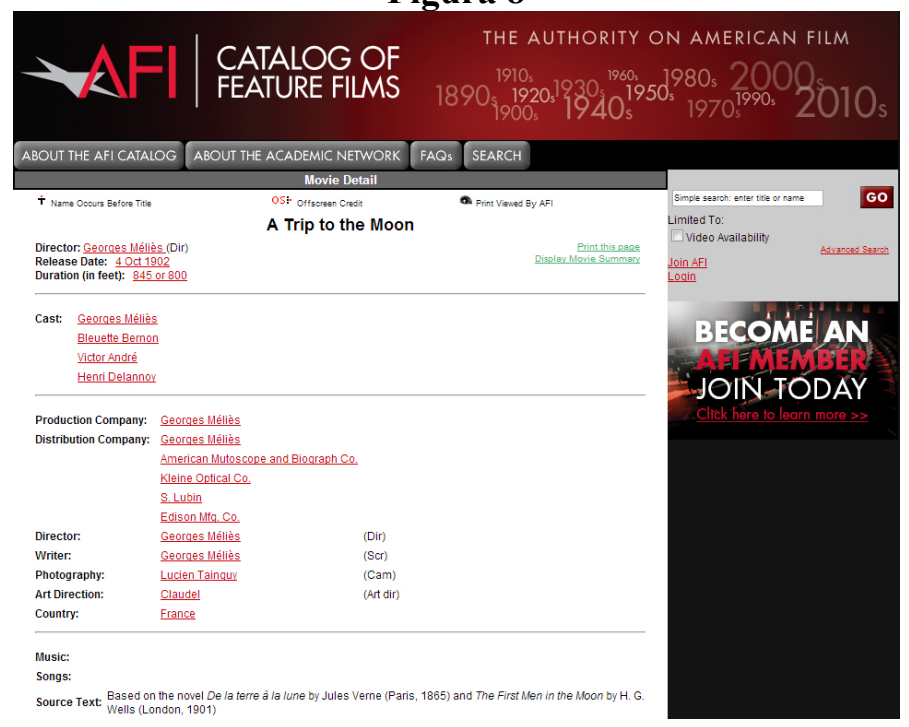

Por parte del British Film Institute, Screenonline (http://www.screenonline.org.uk) es la vía de acceso al mayor archivo de datos e imágenes en movimiento relativo al Reino Unido. No sólo es posible rescatar registros de películas concretas sino también amplios estudios y biografías de quiénes son parte imprescindible del cine inglés, en los que se incluyen enlaces a fichas de producciones relevantes

Previo registro es posible acceder al visionado online de las cintas o al menos el fragmento que de ellas se conserva. Los datos técnicos que se proporcionan son básicos y comunes a los señalados en casos anteriores. Las sinopsis argumentales están concienzudamente elaboradas, muy descriptivas y la entrada tiene, en su cuerpo principal, un texto que contextualiza la cinta y aporta una visión histórica de la misma, donde se destaca su contribución a la cinematografía, qué papel tiene en la filmografía de su director y diversos datos de interés para los historiadores e investigadores 
sobre cine, especialmente de sus primeros años (un ejemplo de ello lo tenemos en la figura 9, con la ficha de Rough Sea at Dover (Acres, 1895).

\section{Figura 9}

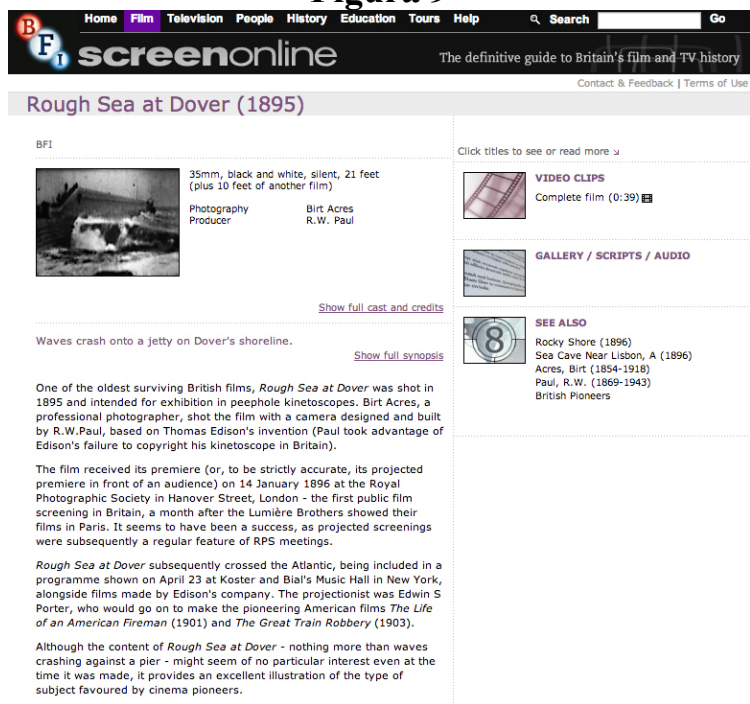

Filmportal (http://www.filmportal.de/), del Deutsche Filminstitut, es una base de datos con más de 70.000 registros diferentes de películas de ficción alemanas desde 1895. Aunque se trata de la gran base de datos online de la cinematografía alemana, en relación a los primeros tiempos del cinematógrafo los datos que se proporcionan no son muy abundantes más allá del título de la vista, año de producción, operador de cámara, director, formato y otros detalles técnicos (tal como muestra la figura 10 con la ficha de Am Alexander-Platz in Berlin (Messer, 1897).

\section{Figura 10}

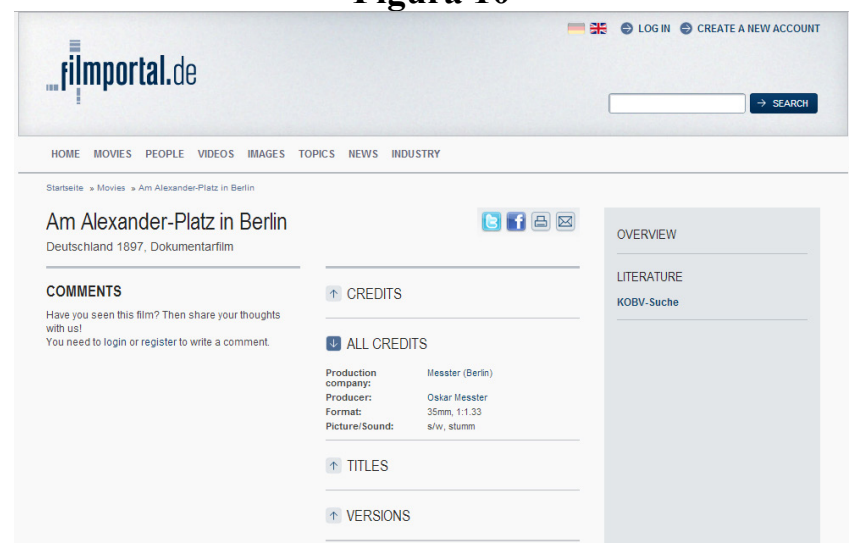


En el caso español nos encontramos con la carencia, por parte de Filmoteca Española y del Ministerio de Cultura, de una gran base de datos en línea que ofrezca la riqueza de contenidos y recursos que hemos visto en el ámbito anglosajón para abarcar al completo la producción de cine español desde sus orígenes (al margen de que se conserven o no copias e incluso fragmentos). La página del Ministerio de Cultura (http://www.mcu.es/cine/CE/BBDDPeliculas/BBDDPeliculas_Index.html) proporciona acceso abierto a la base de datos de películas clasificadas para su exhibición en salas, donde la presencia de títulos de los primeros años de existencia del cinematógrafo es muy escasa, así como los datos proporcionados de los mismos, los cuales podríamos calificar de esenciales y básicos (tal como la figura 11 nos muestra a propósito de Secreto de confesión (Baños, 1906).

\section{Figura 11}

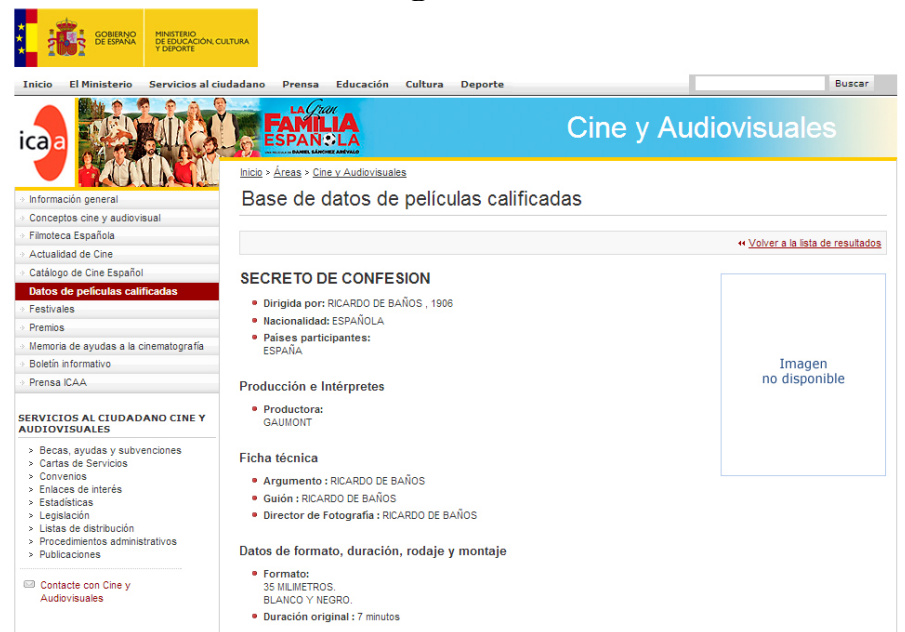

\section{Otras bases de datos}

Al margen de las institucionales, existen otras iniciativas de gran interés. Por su ambición y amplitud destaca Cinema Context (http://www.cinemacontext.nl/), creada por Karel Dibbets y la Universidad de Amsterdam. Abarca todo lo concerniente a la distribución y exhibición cinematográfica en Holanda desde 1896. Sus cinco bases de datos (películas, cines y salas de proyección, programas, nombres propios y compañías) reúnen 107.041 programaciones, 45.612 fichas de cintas, 1625 cines distintos, 48.574 expedientes de censura, 4290 personalidades y 1623 empresas cinematográficas, entre otros datos. Su interés radica el conocer datos de exhibición de cualquier película en suelo holandés (en la figura 12 se muestra la ficha de Aladin et la lampe merveilleuse (Pathé, 1900). 
Figura 12

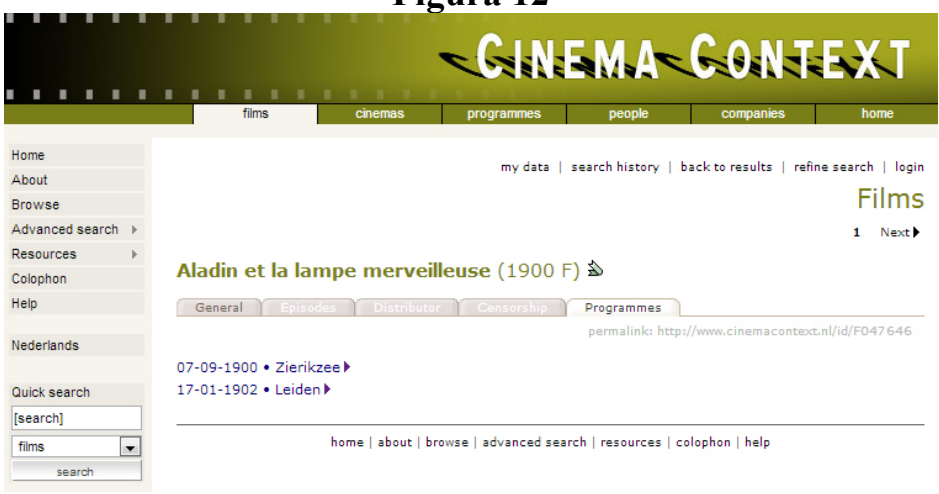

Una base de datos de carácter más internacional y amplia en cuanto a temporalidad es The Complete Index of World Film since 1895 (http://www.citwf.com/indexx. asp); la navegación es posible realizarla por títulos de películas, profesionales, año, país de origen, compañía de producción, género y serie. En el ámbito de los primeros años del cine arroja abultados resultados de búsqueda y aunque los datos proporcionados por las fichas son muy básicos, es indudable su utilidad por la cobertura internacional que tiene.

La Cineteca del Friuli mantiene una base de datos, más restringida en cuanto a la temporalidad, con todos los films exhibidos en el Festival de Cine Mudo de Pordenone (http://www.cinetecadelfriuli.org/gcm/ed_precedenti/screenings_db.html); aunque los fondos se limiten a causa de ello no dejan de tener interés por cuanto suponen conocer producciones cinematográficas que no se han perdido con el paso del tiempo y que aún permanecen (véase como ejemplo la figura 13 con los resultados arrojados de la búsqueda de Segundo de Chomón). Los datos proporcionados no son muy pródigos en detalles más allá de elementos básicos; lo que quizás sea más interesante si necesitamos visionar el material (y no estuviera distribuido en vídeo) es que se señala el archivo que proporcionó la copia en $35 \mathrm{~mm}$. para su proyección.

Otras secciones de la Library of Congress de los Estados Unidos, al margen de la dedicada a Edison, son de interés para las investigaciones en el cine primitivo; entre ellas se encuentra la dedicada a los orígenes del cine de animación americano (http://memory.loc.gov/ammem/oahtml/oahome.html), una base de datos con un arco temporal que se extiende de 1900 a 1921. La guerra de Cuba en imágenes en movimiento también tiene espacio en el Memory Collections (http://memory.loc.gov/ ammem/sawhtml/sawhome.html); la colección se compone de 68 cintas que abarcan este conflicto bélico entre Estados Unidos y España, que se amplía también a vistas tomadas durante la revolución de Filipinas. 


\section{Figura 13}

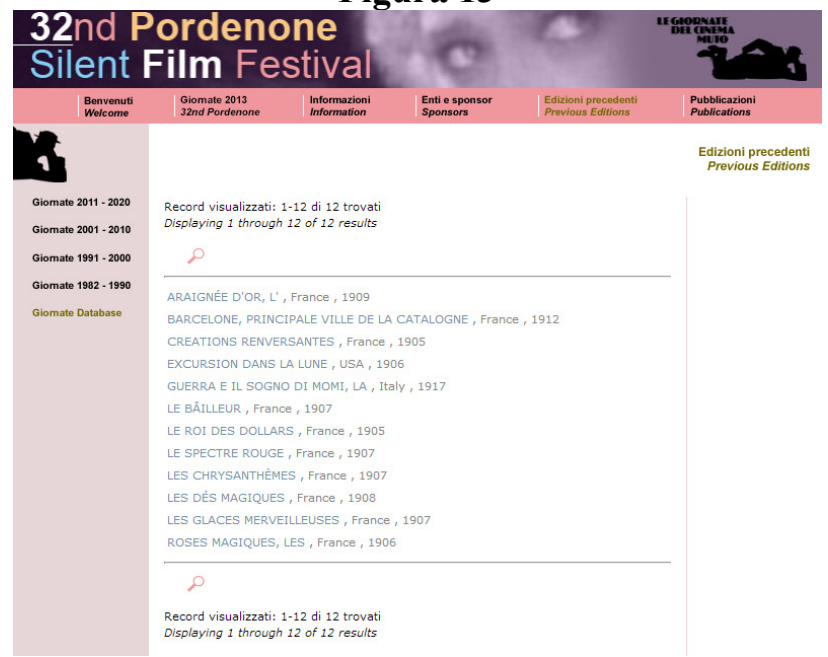

\section{Webs especializadas en el cine de los primeros tiempos}

Existen infinidad de páginas especializadas en múltiples aspectos tanto de los orígenes del cine como del periodo que transcurre hasta la llegada del sonoro. Relacionarlas todas excedería el espacio disponible, así que desde la experiencia y la práctica se van a resaltar algunas de las más sobresalientes por la calidad y cantidad de la información que contienen sobre los primeros años del cine.

The Bioscope (http://thebioscope.net/) es un blog con múltiples entradas, muy exhaustivas, dedicadas a varias facetas del estudio y conocimiento de las tres primeras décadas del cine. Incluye múltiples enlaces a bases de datos, repertorios videográficos en línea, repositorios de material hemerográfico, etc.

The History of the Discovery of Cinematography (http://www.precinemahistory. net/), creada por el historiador canadiense Paul Burns, se centra en la historia de la imagen desde el origen de la humanidad hasta 1895. Dentro de un carácter esencialmente divulgativo, es muy profusa en detalles.

Who is Who of Victorian Cinema (http://www.victorian-cinema.net/) es un repertorio biográfico de los perfiles más relevantes de los antecedentes e inmediatos primeros tiempos del cine (1871-1901); son entradas muy bien documentadas que incluyen referencias bibliográficas y enlaces a otros perfiles relacionados con el sujeto objeto de la búsqueda.

Varias webs están dedicadas en exclusiva a un solo protagonista del cine de los primeros tiempos, ya sea Georges Méliès (http://www.melies.eu/ y http://www. 
cinemathequemelies.eu/), los Lumière (http://www.institut-lumiere.org/patrimoine index.html), y Charles Urban (http://www.charlesurban.com/), entre otros.

Tampoco podemos olvidar en este recorrido los sitios web de grupos de investigación centrados en esta etapa del cine, entre los más relevantes a nivel internacional se encuentra el canadiense GRAFICS, Groupe de recherche sur l'avènement et la formation des institutions cinématographique et scénique (http://cri.histart.umontreal.ca/grafics/fr/default.asp).

\section{Acceso a copias bibliográficas digitales}

Internet provee también el acceso a material digitalizado al completo, principalmente en pdf, descargable y de interés para el investigador en varios aspectos de los comienzos del cine para consultarlos desde la comodidad de su lugar de trabajo. El valor de todos ellos es la posibilidad de acceder a la consulta de documentos de difícil acceso y de gran relevancia por cuanto son contemporáneos al periodo estudiado.

La Bibliotheque Numérique du Cinéma (http://www.bibliotheque-numerique-cinema.fr) y Ciné-Ressources (http://www.cineressources.net), catálogo colectivo de las bibliotecas y archivos franceses (Filmoteca Francesa y Filmoteca de Toulousse, entre ellos), son espacios en los que hallar documentos digitalizados. Entre los elementos interesantes que podemos encontrar están especialmente los catálogos impresos, como los de 1903 y 1906-1907 de Animatograph Films de R. W. Paul (http://www.cineressources.net/images/ouv_num/280.pdf) y el de cámaras, proyectores y accesorios de Pathé Frères de $191 \overline{5}$ (http://www.cineressources.net/images/ ouv_num/237.pdf).

The Internet Archive (http://archive.org) tiene, entre otros documentos de interés, varios libros digitalizados desde ejemplares originales, con gran resolución, como The Handbook of Kinetography, the History, Theory, and Practice of Motion Photography and Projection (Colin N. Bennett, 1911, http://archive.org/details/ handbookofkinema00bennuoft), Movies and Conduct (Herbert Blumer, 1933, http:// archive.org/details/moviesandconduct00blumrich), The Film Industry (Davidson Boughey, 1921), Who's Who on the Screen (Charles D. Ford y Milton Silver, 1920, http://archive.org/details/whoswhoonscreen00foxc), y The Cinema: its Present Position and Future Possibilities (1917, http://archive.org/details/cinemaitspresent00natirich), entre otros. De gran interés, por su valor a nivel de contenidos, son los dos catálogos impresos (1894-1912 y 1912-1939) de los fondos filmográficos producidos hasta 1939 de la Library of Congress de los Estados Unidos (http://ia700508. us.archive.org/6/items/motionpict18941912librrich/motionpict18941912librrich. pdf y http://ia601702.us.archive.org/24/items/Motionpict19121939librrich0010/ Motionpict19121939librrich0010.pdf respectivamente), además del National Film Archive Catalogue. Silent Non-Fiction Films 1895-1934, editado por el British Film Institute en 1960 (http://ia601204.us.archive.org/8/items/nationalfilmarch00nati/ 
nationalfilmarch00nati.pdf). The Internet Archive hace posible descargar y/o visualizar todos sus documentos en varios formatos: pdf color o blanco y negro, epub, kindle, texto, etc.

Más catálogos, sobrepasando el medio millar aunque con menor calidad de imagen (digitalizados la mayoría de ellos a partir de fotocopias en blanco y negro muy deficientes), son accesibles en el repositorio de la New Jersey University: New Jersey Digital Highway (http://www.njdigitalhighway.org/search/results.php?key=NJD$\mathrm{H} \& \mathrm{c}[]=$ rucore00000001079). Entre sus fondos se encuentran principalmente materiales editados por Edison, Biograph, algo de Lumière y algunos productores menores norteamericanos.

Sin recurrir a proveedores y repositorios de abono, también es posible encontrar en formato de libre acceso valiosos recursos bibliográficos sobre los orígenes y primeros tiempos del cine desde distintas perspectivas.

En la página del profesor David Bordwell (http://www.davidbordwell.net/books/) pueden descargarse algunos de sus libros en pdf, completos, en su formato original de publicación y en inglés, así como fragmentos de otros. Entre los primeros cabe destacar Exporting Entertainment: America in the World Film Market 1907-1934 (en colaboración con Kristin Thompson, British Film Institute, 1985).

Un completo estudio del emblemático film Le Voyage dans la Lune de Georges Méliès, editado a propósito su reciente y laboriosa restauración en color, puede encontrarse también por la red. Se trata de Le Couleur Retrouvée du Voyage dans la Lune / A Trip to the Moon. Back in color (Séverine Wemaere y Gilles Duval, Fondation Groupama Gan pour le Cinéma, Fondation Technicolor pour le Patrimoine du Cinéma, 2011), descargable en http://www.fondation-groupama-gan.com/fileadmin/user_upload/pdf/livretvoyagedanslalune.pdf. Otra obra de interés sobre los primeros tiempos del cine en acceso libre es Historie Encyclopédique du Cinéma. I Le Cinema Français 1895-1929 (René Jeanne y Charles Ford, 1947), disponible en http://ia601203.us.archive.org/33/items/histoireencyclop00jean/histoireencyclop00jean.pdf

\section{Conclusiones}

Aunque con carencias, debido a que se echa en falta el acceso libre al catálogo de Lumière et fils., actualmente únicamente disponible en formato impreso (Aubert y Seguin, 1995), además de una base de datos española de referencia, como se ha comentado, es indudable el potencial que internet encierra para la investigación sobre cine, especialmente en nuestro objeto de estudio: sus orígenes y primeros tiempos.

Abundan los recursos, de los cuales tan sólo se han mostrado los de mayor interés para el investigador, los cuales pueden resumirse en dos tipologías: bases de datos y materiales originales en formato digital. 


\section{Bibliografía}

AMERICAN FILM INSTITUTE (1988). Catalog of Motion Pictures Produced in the United States: Feature Films, 1911-1920. Berkeley: University of California Press.

AUBERT, M.; SEGUIN, J. C. (1995). La production cinématographique des Frères Lumière. Paris: Centre Nacional de la Cinématographie, Bibliothéque du Film.

BOUSQUET, H. (1994). "L'age d'or". En KERMABON, J. (ed.) (1994). Pathé: premier empire du cinéma. Paris: Centre Georges Pompidou. p. 48-73.

(1994-2004). Catalogue Pathé des anées 1896 á 1914. Bures-Sur-Yvette: Editions Henri Bousquet.

BOWSER, E. (ed.) (1973). Biograph Bulletins: 1908-1912. New York: Farrar, Strauss and Giroux.

BRITISH FILM INSTITUTE (1966). National Film Archive Catalogue. Part III Silent Fiction Films (1895-1930). London: British Film Institute.

Catalog of Copyright Entries: Motion Pictures, 1912-1939 (1953). Washington: Library of Congress, Copyright Office.

Catalog of Copyright Entries: Motion Pictures, 1894-1912 (1955). Washington: Library of Congress, Copyright Office.

CHIRAT. R. (ed.) (1995). Catalogue des Films Français de Fiction de 1908-1918. Paris: Cinémathéque Française.

D'HUGUES, P.; MULLER, D. (1986). Gaumont: 90 ans de cinema. Paris: Ramsay, Cinémathèque Française.

GAUDREAULT, A. (2011). Film and Attraction: from Kinematography to Cinema. Chicago: University of Illinois Press.

GIFFORD, D. (2001). The British Film Catalogue, 1895-1994. London: Fitzroy Dearborn.

MALTHÊTE, J.; MALTHÊTE-MÉLIÈS, M.; QUÉVRAIN, A. M. (1981). Essai de Reconstitution du Catalogue Français de la Star-Film, suivi d'une Analyse Catalographique des Films de Georges Méliès Recensés en France. Bois D'Arcy: Publications Service des Archives du Film du CNC.

MUSSER, C. (ed.) (1984). Motion Picture Catalog by American Producers and Distribuitors, 1894-1908. Frederick: University Publications of America.

(1997). Edison Motion Pictures, 1890-1900. An Annotated Filmography. Washington: Smithsonian Institution Press.

NIVER, K. R. (1967). Motion Pictures from Library of Congress. Paper Print Collection 1894-1912. Berkeley, Los Angeles: University of California Press.

(ed.) (1973). Biograph Bulletins: 1896-1908. Los Angeles: Locare Research Group.

SAVADA, E. (ed.) (1995). The American Film Institute Catalog of Motion Pictures Produced in the United States: Film Beginnings, 1893-1910. New Jersey: Scarecrow Press. 
Páginas web

Base de datos de películas calificadas del Ministerio de Cultura de España, http:// www.mcu.es/cine/CE/BBDDPeliculas/BBDDPeliculas_Index.html [23-082013].

Bibliotheque Numérique du Cinéma, http://www.bibliotheque-numerique-cinema.fr [23-07-2013].

Charles Urban, http://www.charlesurban.com/ [08-08-2013].

Ciné-Ressources, http://www.cineressources.net [09-08-2013].

Cinema Context, http://www.cinemacontext.n1/ [26-07-2013].

Cinémathèque Méliès, http://www.cinemathequemelies.eu/ [08-08-2013].

David Bordwell, http://www.davidbordwell.net/ [10-08-2013].

Edison Manufacturing Company, American Memory Collections, Library of Congress, http://memory.loc.gov/ammem/edhtml/edhome.html [16-08-2013].

Filmportal, Deutsche Filminstitut, http://www.filmportal.de/ [22-08-2013].

Gaumont Pathé Archives, http://www.gaumontpathearchives.com/ [12-07-2013].

Georges Méliès, http://www.melies.eu/ [08-08-2013].

GRAFICS, Groupe de recherche sur l'avènement et la formation des institutions cinématographique et scénique, http://cri.histart.umontreal.ca/grafics/fr/default. asp [08-08-2013].

Lumière Institut, http://www.institut-lumiere.org/patrimoine index.html, [08-082013].

Origins of American Animation, America Memory Collections, Library of Congress, http://memory.loc.gov/ammem/oahtml/oahome.html [10-08-2013].

Pathé Frères / Fondation Jérôme Seydoux Pathé, http://filmographie.fondation-jeromeseydoux-

pathe.com/ [23-08-2013].

Pordenone Silent Film Festival, Cineteca del Friuli, http://www.cinetecadelfriuli.org/ gcm/ed_precedenti/screenings_db.html [28-08-2013].

Screenonline, British Film Institute, http://www.screenonline.org.uk [21-08-2013].

Silent Movie, American Film Institute, http://www.afi.com/members/catalog/silentHome.aspx?s=1 [22-08-2013].

The Bioscope, http://thebioscope.net/ [21-08-2013].

The Complete Index of World Film since 1895, http://www.citwf.com/indexx.asp [29-07-2013].

The History of the Discovery of Cinematography, http://www.precinemahistory.net/ [25-07-2013].

The Internet Archive, http://archive.org [09-08-2013].

The Spanish American War in Motion Pictures, America Memory Collections, Library of Congress http://memory.loc.gov/ammem/sawhtml/sawhome.html [12-08-2013].

Who is Who of Victorian Cinema, http://www.victorian-cinema.net/ [10-08-2013]. 


\section{La autora}

Mónica Barrientos-Bueno. Profesora Ayudante Doctora de la Universidad de Sevi1la. Investigadora de diversas facetas del audiovisual, con especial relevancia en los orígenes del cine en Sevilla. Monografías: Inicios del cine en Sevilla (1896-1906). De la presentación en la ciudad a las exhibiciones continuadas (Universidad de Sevilla, 2006) y Antonio de la Rosa, empresario pionero del cinematógrafo en Sevilla (19021907) (Padilla, 2003). Artículos recientes: "De Sevilla a la luna. Vistas animadas de Star-Film en el cinematógrafo sevillano (1896-1906)" (Comunicación no 11, 2013) y "Pathé Frères en Sevilla. Filmes exhibidos durante la primera etapa de la compañía" (Archivos de la Filmoteca no 72, 2013). 